\title{
Pengaruh Screen Layer Breakwater Terhadap Tinggi Run UP Gelombang pada Revetmen
}

\author{
Budiman $^{1, a}$ \\ ${ }^{1}$ Teknik Sipil, Politeknik Negeri Fakfak, Jl. Imam Bonjol Atas, Air Merah, Wagom, Fakfak, 98612, Indonesia \\ a budiman@polinef.id
}

\begin{abstract}
Abstact -Erosion that occurs in revetment by waves and currents is a serious problem along coastal and inland shore [1]. The aims of the study are to obtain influential parameter, to reduce the height of run up in the revetmet and get a non dimensional parameter of the relationship between the wave height and the wave run up on the revetment. The research is an experimental research with 2D physical model simulation, conducted in the laboratory of with some configurations of screen layer breakwater configuration models made from textile fabric with density and number of layer of different models. The model scale was 1:10 with three variations for models ((M1SL, M2SL, and M3SL) with variations of wave length and wave height, on some level of depth: 20,15 , and $10 \mathrm{~cm}$. The results of the research indicated that the parameters found in this study are wave period $(\mathrm{T})$, wave height $(\mathrm{H})$, water depth $(\mathrm{d})$, screen density $(\zeta)$, the number of layers $(N)$ and the distanceof the screen $(\mathrm{Xm})$. The run up tend to decrease as the screen density value has smaller number of layers $(N)$ and the distanceof the screen $(\mathrm{Xm})$. In general, the study indicated that the stake of the screen layer can reduce the height of the run up in the revetment structure. The slope $\tan \theta 30^{\circ}$ was $33 \%$ and produces non regression equation that shows the relationship between the dimensionless parameter $\psi$ with run up $(\mathbf{R u} / \mathbf{H})$, obtained $\mathbf{R u} / \mathbf{H}=\mathbf{a} \Psi^{\mathrm{b}}$, where $\Psi=\left(\operatorname{Irr} . \zeta_{\times} N_{*} \frac{\text { Xmd }}{L^{2}}\right) ;$ a and $b$ respectively 2.9935 and 0.1293.
\end{abstract}

Keywords - run up, screen layer break water, revetment.

Abstrak - Erosi yang terjadi pada revetmen oleh gelombang dan arus adalah masalah serius disepanjang pesisir pantai dan pedalaman [1]. Penelitian ini bertujuan untuk mendapatkan parameter yang berpengaruh terhadap pengurangan tinggi run up pada revetment dan mendapatkan hubungan bilangan tak berdimensi antara gelombang datang dan run up gelombang pada revetment. Penelitian ini bersifat eksperimental dengan uji fisik yang dilakukan di saluran gelombang 2-D pada Laboratorium dengan membuat beberapa konfigurasi model screen layer breakwater yang terbuat dari kain tekstil dengan kerapatan, jumlah lapis dan jarak model yang berbeda. Skala model digunakan adalah $1: 10$, dengan tiga variasi model (M1SL, M2SL, dan M3SL) dan variasi panjang gelombang serta tinggi gelombang dengan simulasi pada beberapa kedalaman, yaitu $20 \mathrm{Cm}, 15 \mathrm{Cm}$, dan $10 \mathrm{Cm}$. Hasil penelitian menujukkan bahwa parameter yang berpengaruh adalah periode gelombang $(\mathrm{T})$, tinggi gelombang datang $(\mathrm{H})$,

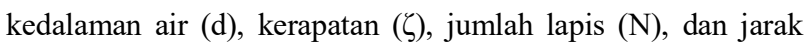
screen $(\mathrm{Xm})$, run up yang terjadi cenderung menurun dengan semakin besar nilai kerapatan, jumlah lapis dan jarak screen bertambah. Secara umum hasil yang diperoleh menunjukkan bahwa dengan adanya screen layer tersebut dapat mengurangi tinggi runup pada struktur revetmen dengan kemiringan $\tan \theta$ $30^{\circ}$ sebesar $33 \%$ dan menghasilkan persamaan nonregresi yang menunjukkan hubungan parameter tak berdimensi antara Error! Reference source not found. dengan run up $(\mathrm{Ru} / \mathrm{H})$, diperoleh Error! Reference source not found., dimana Error! Reference source not found.; a dan b masing-masing 2,9935 dan 0,1293.

Kata Kunci-run up, screen layer breakwater, revetment

\section{Pendahuluan}

Struktur perlindungan pantai (revetment) merupakan struktur bangunan yang memisahkan daratan dan perairan pantai, terutama berfungsi sebagai pelindung pantai terhadap erosi dan limpasan gelombang (overtopping) ke darat. Kelemahan dari struktur revetment adalah potensi terjadinya kerusakan pada kaki bangunan oleh tinggi Run Up yang cukup besar, sehingga dapat mengganggu stabilitas bangunan. Oleh karena itu, pada bagian kaki bangunan ini harus dibuatkan suatu pelindung erosi (toe protection) yang cukup baik. Pelindung kaki atau toe protection pada revetmen berfungsi untuk mereduksi kenaikan air (Run Up) yang dapat merusak bangunan. Run Up gelombang terjadi pada saat gelombang datang bergerak menuju ke pantai dan membentur bangunan sebagian energi gelombang akan diubah menjadi gerakan air yang meluncur kearah lereng bangunan yang dapat menimbulkan kecepatan aliran balik yang cukup besar yang dapat menarik butiran tanah di dasar kaki bangunan. Keadaan ini dapat mengakibatkan rusak/runtuhnya bangunan [2]. 
Penelitian skala laboratorium telah dilakukan sebelumnya untuk mendapatkan persamaan wave Run $U p$ yang merupakan fungsi dari irribaren number dengan menghubungkan Non Dimensional Parameter dan nilai Run Up gelombang. Dari eksperimen tersebut menghasilkan persamaan untuk Run $U p$ gelombang berupa kurva dalam bentuk hubungan parameter tak berdimensi yang dapat diaplikasikan di lapangan [3], [4].

Hal tersebut diatas menjadi acuan untuk melakukan penelitian tentang perlindungan pantai agar tetap aman dengan menggunakan pelindung kaki screen layer Breakwater. Penelitian ini bertujuan untuk mendapatkan parameter yang berpengaruh terhadap Run $U p$ dan mendapatkan hubungan bilangan tak berdimensi antara gelombang datang dan Run Up gelombang pada revetmen.

\section{Metode Penelitian}

\section{A. Lokasi Penelitian}

Penelitian ini dilaksanakan di Laboratorium Teknik Kelautan Fakultas Teknik Universitas Hasanuddin dengan menggunakan metode eksperimental. Ekperimen ini merupakan uji fisik di saluran gelombang 2-D yang dilengkapi penggerak gelombang dengan panjang flume $18,45 \mathrm{~m}$, lebar 1,22 dan tinggi $1,22 \mathrm{~m}$, slot screen dari besi, impermeable revetment dari plat baja dengan kemiringan $30^{\circ}$, screen layer dari material kain tekstil serta alat ukur untuk mengukur tinggi gelombang, Run Up dan Run Down dengan lay out saluran percobaan 2D seperti Gambar 1.

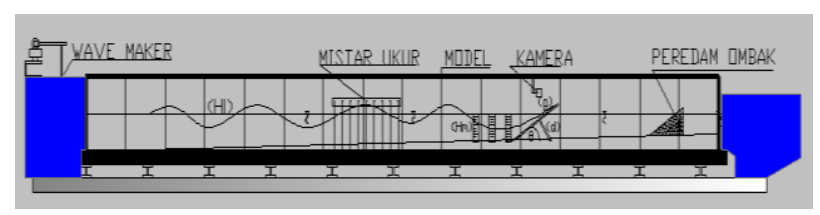

Gambar 1. Lay out saluran percobaan 2D

Pelaksanaan simulasi percobaan dilakukan dengan :

1. Melakukan kalibrasi peralatan (pengaturan pulley untuk periode dan panjang gelombang, stroke untuk tinggi dan cepat rambat gelombang, serta pengaturan posisi revetmen) untuk pencatatan tinggi gelombang $(\mathrm{H})$.
2. Setelah komponen siap, simulasi gelombang dimulai tanpa model dengan membangkitkan gelombang dengan tuas daya pada kontrol pembangkit gelombang.

3. Kemudian dilanjutkan dengan memasang model di tengah-tengah wave flume didepan revetmen.

4. Tinggi gelombang datang diukur di depan posisi model pada 9 titik sedang tinggi run up dan run down gelombang diukur pada revetmen.

5. Prosedur 1 sampai 5 dilanjutkan secara berulang pada model lain untuk masingmasing model, dengan variasi kerapatan, jumlah lapis, jarak, parameter stroke untuk tinggi gelombang, fully untuk periode gelombang dan variasi kedalaman air.

\section{B. Tahapan Penelitian}

Tahapan dalam pelaksanaan penelitian ini seperti Gambar 2.

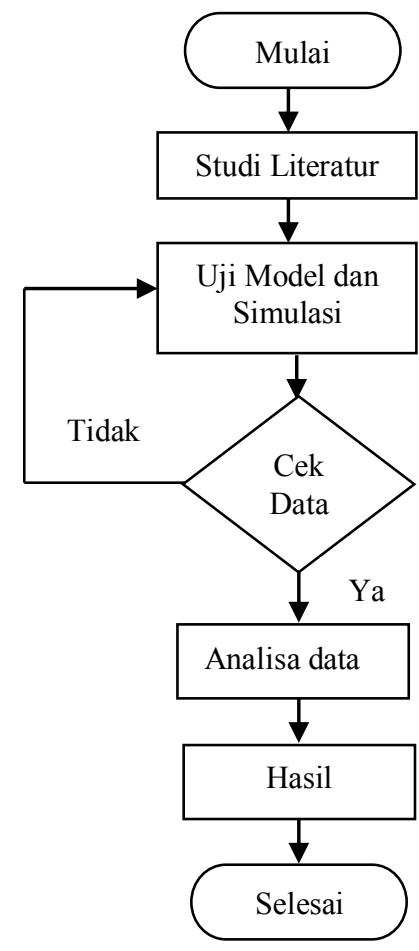

Gambar 2. Bagan Alir Tahapan Penelitian

\section{Rancangan Sampel Penelitian}

Rancangan sampel dalam penelitian ini adalah menggunakan screen layer dari kain tekstil, impermeable revetment dari plat baja, alat ukur gelombang dari mistar kayu. Parameter penelitian 
terdiri dari parameter tetap yaitu run-up $(R u)$ dan run-down $(R d)$ dan parameter bebas yaitu kerapatan model (Error! Reference source not found.), jumlah lapis screen $(\mathrm{N})$, jarak screen $(\mathrm{Xm})$, kedalaman air (d) seperti Tabel 1.

Data-data yang diperoleh diolah menggunakan analisa dimensi untuk memperoleh hubungan antar parameter yang akan menghasilkan bilangan tak berdimensi [5]. Metode analisa dimensi yang digunakan dalam penelitian ini adalah metode Langhaar.

\begin{tabular}{|c|c|c|c|c|}
\hline \multicolumn{5}{|c|}{ Tabel 1 Sampel penelitian } \\
\hline No. & $\begin{array}{c}\text { Jml Lapis } \\
\text { Model (N) }\end{array}$ & $\begin{array}{l}\text { Kedalaman } \\
\text { air (d) } \mathrm{cm}\end{array}$ & $\begin{array}{c}\text { Variasi } \\
\text { kerapatan } \\
\text { (Error! } \\
\text { Reference } \\
\text { source not } \\
\text { found.) } \\
\end{array}$ & $\begin{array}{c}\text { Jarak } \\
\text { screen } \\
(\mathrm{Xm}) \mathrm{cm}\end{array}$ \\
\hline 1 & MSL & $10,15,20$ & 0 & 0 \\
\hline 2 & $\begin{array}{l}\text { M1SL1 } \\
\text { M1SL2 } \\
\text { M1SL3 }\end{array}$ & $10,15,20$ & 0,855 & $\begin{array}{c}5 \\
10 \\
15\end{array}$ \\
\hline 3 & $\begin{array}{l}\text { M2SL1 } \\
\text { M2SL2 } \\
\text { M2SL3 }\end{array}$ & $10,15,20$ & 0,565 & $\begin{array}{c}5 \\
10 \\
15 \\
\end{array}$ \\
\hline 4 & $\begin{array}{l}\text { M3SL1 } \\
\text { M3SL2 } \\
\text { M3SL3 }\end{array}$ & $10,15,20$ & 0,29 & $\begin{array}{c}5 \\
10 \\
15\end{array}$ \\
\hline
\end{tabular}

\section{Penentuan nilai Irribaren}

Penentuan nilai Run Up dan Run Down dari fungsi bilangan Irribaren untuk berbagai jenis lapis lindung menurut Irribaren

$$
I r=\frac{\tan \theta}{\left(\frac{H}{L_{0}}\right)^{0.5}}
$$

dengan :

Ir $\quad$ = Bilangan Irribaren

$\theta=$ Sudut kemiringan sisi bangunan pemecah gelombang

$H \quad=$ tinggi gelombang di lokasi bangunan

$L_{0} \quad=$ panjang gelombang di laut dalam

\section{Hasil dan Pembahasan}

1. Tinggi dan Panjang Gelombang

Hasil perhitungan tinggi dan panjang gelombang (L) berdasarkan periode gelombang (T) dan kedalaman air (d) seperti Tabel 2 dan Tabel 3.

Tabel 2. Hasil perhitungan panjang gelombang (L), periode (T) dan kedalaman air (d)

\begin{tabular}{|c|c|c|c|c|c|}
\hline \multirow{3}{*}{$\begin{array}{l}\text { No } \\
\text { Perc }\end{array}$} & \multirow{3}{*}{$\begin{array}{l}\text { Nama } \\
\text { Model }\end{array}$} & \multicolumn{2}{|c|}{$\begin{array}{c}\text { Kombinasi } \\
\text { Model-I }\end{array}$} & \multirow{2}{*}{$\begin{array}{c}\text { Periode } \\
\mathrm{T} \\
\end{array}$} & \multirow{2}{*}{$\mathrm{L}$} \\
\hline & & $\mathrm{d}$ & $\mathrm{Xm}$ & & \\
\hline & & $\mathrm{cm}$ & $\mathrm{cm}$ & (detik) & $(\mathrm{cm})$ \\
\hline 1 & \multirow{2}{*}{ M1SL1 } & 20 & 5 & 1,02 & 124,40 \\
\hline 2 & & 20 & 5 & 1,08 & 133,82 \\
\hline 3 & \multirow{2}{*}{ M1SL2 } & 20 & 10 & 1,02 & 124,40 \\
\hline 4 & & 20 & 10 & 1,08 & 133,82 \\
\hline 5 & \multirow{2}{*}{ M1SL3 } & 20 & 15 & 1,02 & 124,40 \\
\hline 6 & & 20 & 15 & 1,08 & 133,82 \\
\hline
\end{tabular}

Tabel 3. Hasil perhitungan tinggi gelombang datang (Hi), panjang gelombang (L), hubungan $\mathrm{Hi} / \mathrm{L}$ dan Koefisien refraksi $(\mathrm{Kr})$

\begin{tabular}{|c|c|c|c|c|c|}
\hline $\begin{array}{c}\text { No } \\
\text { Perc }\end{array}$ & $\begin{array}{c}\text { Nama } \\
\text { Model }\end{array}$ & $\mathrm{Hi}$ & $\mathrm{L}$ & $\mathrm{Hi} / \mathrm{L}$ & $\mathrm{Kr}$ \\
\hline 1 & \multirow{3}{*}{ M1SL1 } & 8,00 & 124,40 & 0,064 & 0,500 \\
\cline { 4 - 6 } & 6,50 & 133,82 & 0,049 & 0,538 \\
\hline 2 & \multirow{2}{*}{ M1SL2 } & 7,50 & 124,40 & 0,060 & 0,467 \\
\cline { 4 - 6 } & & 7,00 & 133,82 & 0,052 & 0,429 \\
\hline 4 & \multirow{2}{*}{ M1SL3 } & 6,25 & 124,40 & 0,050 & 0,440 \\
\cline { 4 - 6 } & 5 & 5,75 & 133,82 & 0,047 & 0,391 \\
\hline
\end{tabular}

\section{Analisa Dimensi}

Berdasarkan metode Langhaar, maka parameter yang dianalisa yaitu : parameter tak bebas (dependent paramater) : $R u$ dan $R d$, paramater yang diubah-ubah selama percobaan : $H$, $T, X m, N$, dan paramater lain : $g, d$

Dari analisa parameter tersebut, diperoleh persamaan Non Dimensional Parameter (NDP) tinggi run-up $(R u)$ sebagai berikut :

$$
\frac{R u}{H}=f\left(\operatorname{Irr} \cdot \zeta \cdot N \cdot \frac{X m \cdot d}{L^{2}}\right)
$$

Dengan cara yang sama, maka akan diperoleh parameter tinggi run-down $(R d)$ sebagai berikut :

$$
\frac{R d}{H}=f\left(\operatorname{Irr} \cdot \zeta \cdot N \cdot \frac{X m \cdot d}{L^{2}}\right)
$$


3. Tinggi Run Up (Ru) dan Tinggi Run Down $(R d)$

Hasil perhitungan tinggi Run $U p$ dan Run Down seperti Tabel 4.

Tabel 4. Hasil perhitungan Run Up dan Run Down

\begin{tabular}{|c|c|c|c|c|c|}
\hline $\begin{array}{l}\text { No } \\
\text { Perc }\end{array}$ & $\begin{array}{l}\text { Nama } \\
\text { Model }\end{array}$ & $\begin{array}{c}\text { Run } \\
\text { Up } \\
(\mathrm{cm})\end{array}$ & $\begin{array}{c}\mathrm{Ru} / \mathrm{H} \\
(\mathrm{cm})\end{array}$ & $\begin{array}{c}\text { Run } \\
\text { Down } \\
(\mathrm{cm})\end{array}$ & $\begin{array}{c}\mathrm{Rd} / \mathrm{H} \\
(\mathrm{cm})\end{array}$ \\
\hline 1 & \multirow{2}{*}{ M1SL1 } & 13,50 & 1,69 & $-9,00$ & $-1,13$ \\
\hline 2 & & 11,00 & 1,57 & $-8,50$ & $-1,21$ \\
\hline 3 & \multirow{2}{*}{ M1SL2 } & 5,50 & 1,83 & $-4,50$ & $-1,50$ \\
\hline 4 & & 4,75 & 1,58 & $-4,00$ & $-1,33$ \\
\hline
\end{tabular}

4. Hubungan nilai $\mathrm{Hi} / \mathrm{L}$ dengan $\mathrm{Kr}$ terhadap kerapatan ( $\zeta)$, jumlah lapis $(\mathrm{N})$ dan jarak screen layer $(\mathrm{Xm})$ berdasarkan kedalaman.

Grafik hubungan nilai $\mathrm{Hi} / \mathrm{L}$ terhadap $\mathrm{Kr}$

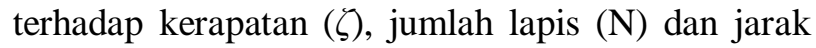
screen layer (Xm) seperti Gambar 3 untuk kedalaman $10 \mathrm{~cm}$, Gambar 4 untuk kedalaman 15 $\mathrm{cm}$ dan gambar 5 untuk kedalaman $20 \mathrm{~cm}$.

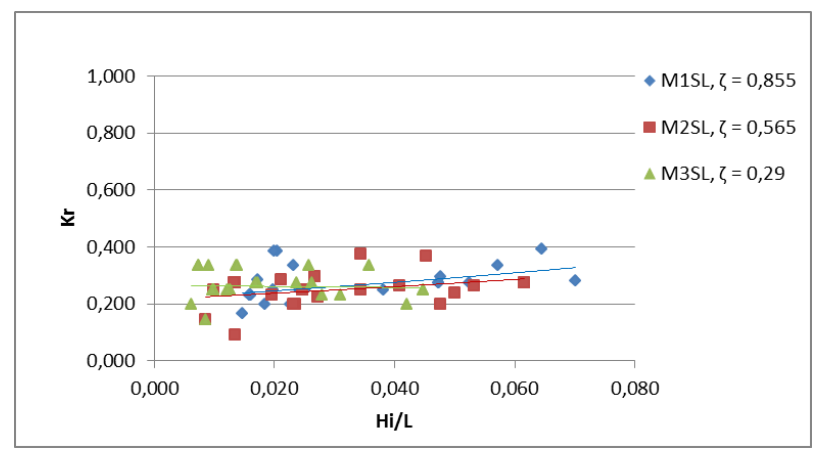

Gambar 3. Hubungan $H i / L$ dengan $K r$ pada model dengan beberapa kerapatan pada kedalaman $10 \mathrm{~cm}$

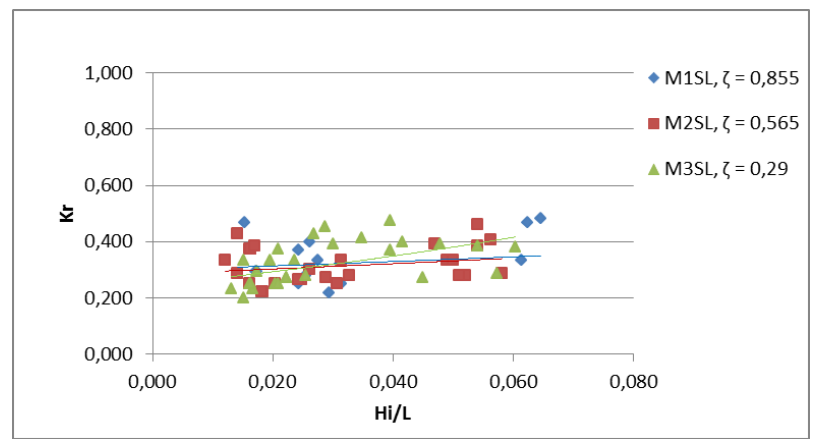

Gambar 4. Hubungan $H i / L$ dengan $K r$ pada model dengan beberapa kerapatan pada kedalaman $15 \mathrm{~cm}$

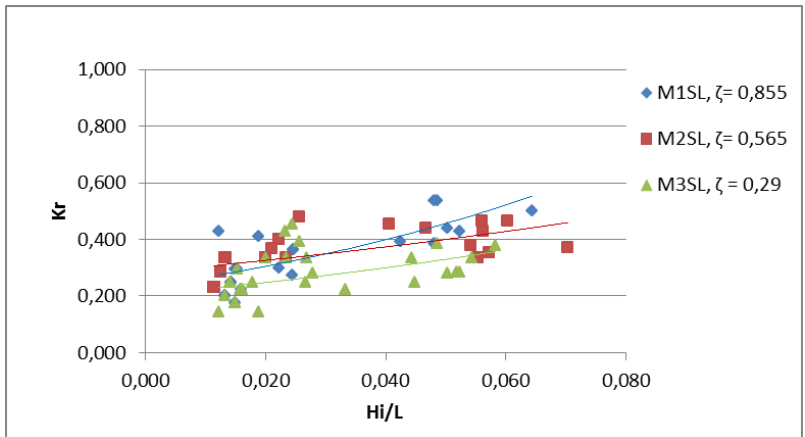

Gambar 5. Hubungan $H i / L$ dengan $K r$ pada model dengan beberapa kerapatan pada kedalaman $20 \mathrm{~cm}$

Berdasarkan Gambar 3, 4 dan 5 menunjukkan grafik hubungan antara $\mathrm{Kr}$ terhadap $\mathrm{Hi} / \mathrm{L}$ untuk variasi jumlah lapis $(N)$ dan Jarak screen layer $(X m)$ pada beberapa kerapatan ( $\zeta$ ). Dari grafik tersebut dapat dijelaskan sebagai berikut :

1) Nilai $\mathrm{Kr}$ cenderung meningkat dengan bertambah besarnya nilai $H i / L$. Hal ini menunjukkan bahwa peningkatan $\mathrm{Hi} / \mathrm{L}$ merepresentasekan adanya tinggi gelombang datang. Peningkatan gelombang datang menyebabkan tinggi refleksi meningkat pula.

2) Pengaruh kerapatan ( $\zeta$ ), jumlah lapis dan jarak screen layer terhadap nilai $\mathrm{Kr}$ cukup signifikan. Hal ini menunjukkan bahwa semakin besar kerapatan, jumlah lapis dan jarak screen layer bertambah, maka gelombang yang direfleksikan menjadi besar.

3) Nilai $K r$ pada kerapatan $(\zeta=0,855)$ lebih besar dibandingkan kerapatan $(\zeta=0,565)$ dan $(\zeta=0,29)$ demikian pula dengan jumlah lapis dan jarak screen layer $(\mathrm{L} 1, \mathrm{Xm}=5 \mathrm{~cm}$ ) dibandingkan jumlah lapis dan jarak screen layer ( $\mathrm{L} 2, \mathrm{Xm}=10$ dan $\mathrm{L} 3, \mathrm{Xm}=15 \mathrm{~cm}$ ), hal ini disebabkan karena gelombang yang teredam relatif kecil pada saat melewati model maka nilai $K r$ besar pada revetmen.

5. Hubungan nilai NDP $=$ Irr. $\zeta$ terhadap $R u n U p$ dan Run Down

Untuk mengkaji pengaruh Irr. $\zeta$ dengan Run Up dan Run Down digunakan 3 simulasi model screen layer dengan tingkat kerapatan $(\zeta)$ dan jumlah lapis $(X m)$ yang berbeda seperti Gambar 6 untuk kedalaman $10 \mathrm{~cm}$, Gambar 7 untuk kedalaman 15 $\mathrm{cm}$ dan Gambar 8 untuk kedalaman $20 \mathrm{~cm}$. 


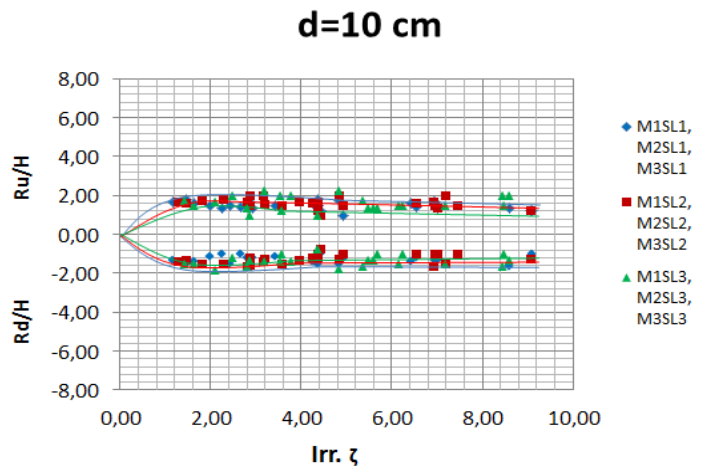

Gambar 6. Hubungan Irr. $\zeta$ dengan $R u / H$ dan $R d / H$ untuk setiap nilai MSL (L1,L2,L3) kedalaman $10 \mathrm{~cm}$
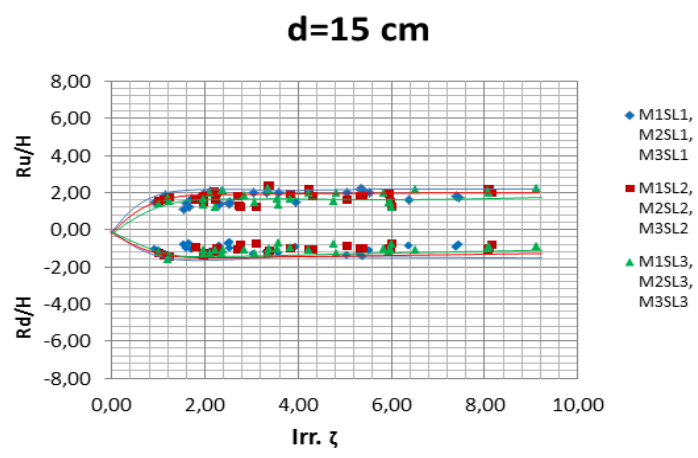

Gambar 7. Hubungan Irr. $\zeta$ dengan $R u / H$ dan $R d / H$ untuk setiap nilai MSL (L1,L2,L3) kedalaman $15 \mathrm{~cm}$

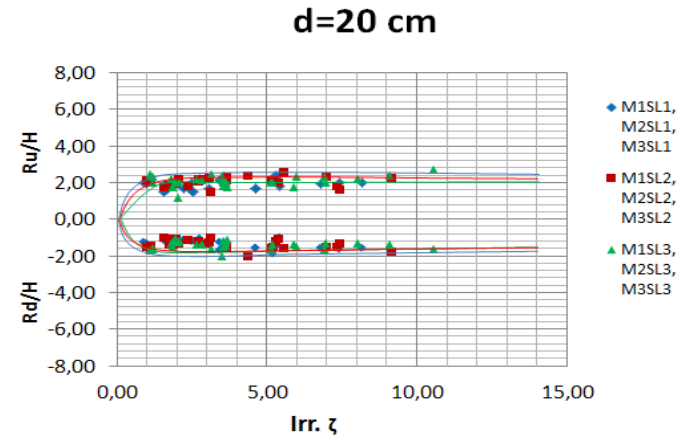

Gambar 8. Hubungan Irr. $\zeta$ dengan $R u / H$ dan $R d / H$ untuk setiap nilai MSL (L1,L2,L3) kedalaman $20 \mathrm{~cm}$

Dari grafik hubungan Irr. $\zeta$ dengan $\mathrm{Ru} / \mathrm{H}$ dan $R d / H$ diperoleh penjelasan sebagai berikut :

1) Nilai $R u / H$ cenderung lebih besar pada nilai M1SL1, dibandingkan pada nilai M1SL2, dan M1SL3, hal ini disebabkan karena nilai kerapatan, jumlah lapis dan jarak screen layer pada model M1SL1 lebih kecil dibandingkan pada model M1SL2 dan M1SL3.

2) Nilai $R d / H$ cenderung semakin besar pada model screen layer lapis satu (M1SL1) dibandingkan model M2SL1 dan M3SL1, hal ini disebabkan karena nilai kerapatan pada M2SL1 dan M3SL1 lebih besar dibandingkan kerapatan M1SL1.

3) Untuk percobaan masing-masing model semakin besar kerapatan jumlah lapis $(\mathrm{N})$ dan jarak screen layer $(\mathrm{Xm})$ bertambah maka efektif mereduksi Run Up dan Run Down.

\section{Pengaruh NDP = Error! Reference source not}

found. terhadap Run $U p$

Nilai Run Up yang diplot dalam bentuk grafik menunjukkan karakteristik sebaran data gabungan dari Irribarren number dengan parameterparameter penelitian yang merupakan Non Dimensional Parameter dan nilai Run Up gelombang. Melihat dari sebaran data tersebut maka dapat diduga bahwa persamaan regresinya bukanlah regresi linier. Hubungan ini menyatakan bahwa Run Up gelombang merupakan fungsi dari bilangan irribaren number, sehingga dari analisa dimensi diperoleh suatu regeresi baru Run $U p$ gelombang seperti Gambar 9.

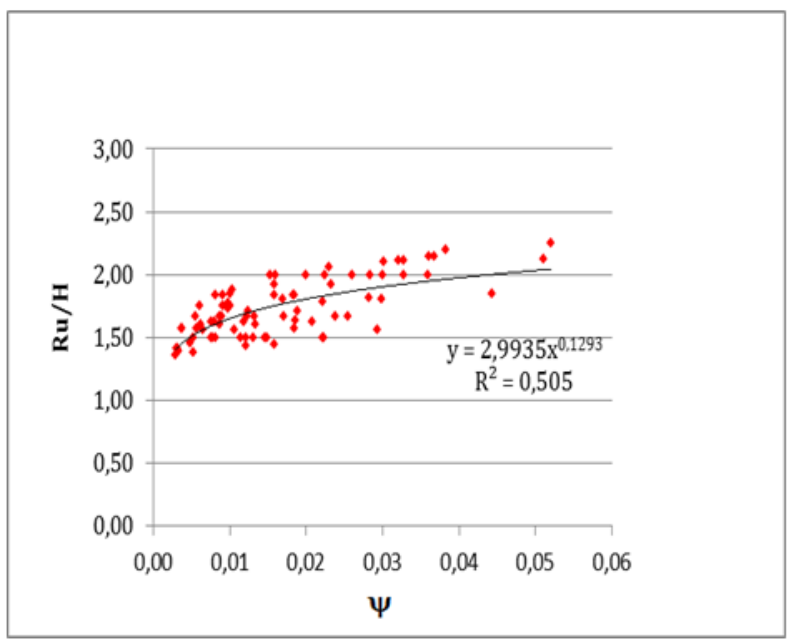

Gambar 9. Kurva hubungan $\psi$ Error! Reference source not found. terhadap nilai $\mathrm{Ru} / \mathrm{H}$

Berdasarkan Gambar 9, bahwa semakin besar nilai $\psi$ maka nilai Run $U p$ semakin besar pula. Hal ini nilai $\psi$ dipengaruhi oleh kerapatan $(\zeta)$ jumlah lapis $(\mathrm{N})$ dan jarak screen layer $(\mathrm{Xm})$, hasil penelitian menunjukkan bahwa Run Up gelombang cenderung mengecil apabila semakin besar kerapatan ( $\zeta)$, jumlah lapis $(N)$ dan Jarak screen layer $(\mathrm{Xm})$ bertambah demikian pula sebaliknya. 
Dari hasil eksperimen dihasilkan hubungan bilangan tak berdimensi antara nilai $\psi$ terhadap nilai $R u / H$ sebagai fungsi dari bilangan Irribaren, sehingga diperoleh persamaan regresi baru untuk nilai $R u / H$ adalah :

$$
\frac{R u}{H}=a \psi^{b}
$$

Dimana : Error! Reference source not found.; dengan nilai koefisien a dan $b$ adalah 2,9935 dan 0,1293

Keterangan :

Irr (Irribaren number), Error! Reference source not found. (kerapatan), $\mathrm{N}$ (jumlah lapis screen layer), jarak screen layer (Xm), d (kedalaman air) dan L (panjang gelombang).

Untuk mengetahui besarnya nilai penyimpangan hasil perhitungan menggunakan formula yang diperoleh terhadap data eksperimen, maka dibuat grafik hubungan antara $\mathrm{Ru} / \mathrm{H}$ estimate dengan $\mathrm{Ru} / \mathrm{H}$ eksperimen seperti Gambar 10.

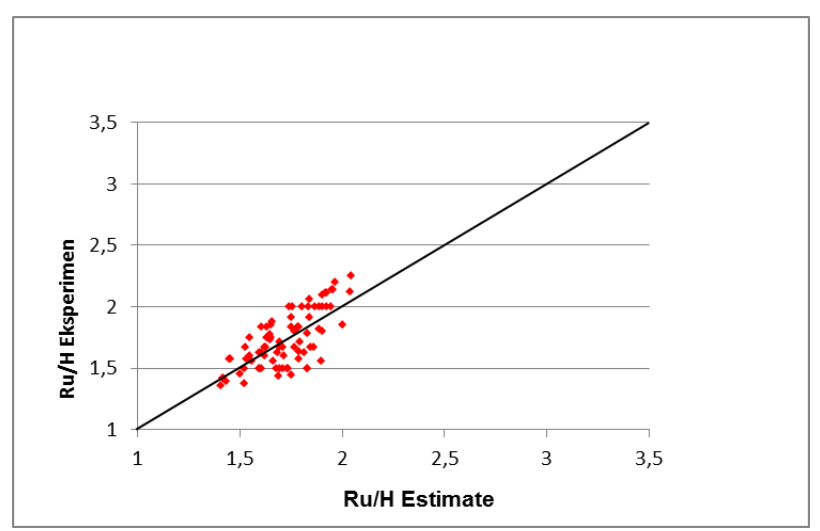

Gambar 2. Kurva hubungan nilai Ru/H estimate dan nilai $R u / H$ eksperimen

Berdasarkan kurva pada gambar 10 menunjukkan karakteristik sebaran data yang merupakan nilai $R u / H$ estimate dengan nilai $R u / H$ eksperimen. Dimana nilai sebaran data hasil eksperimen mendekati kurva teoritik yang dihitung berdasarkan formula.

\section{Kesimpulan dan Saran}

Berdasarkan hasil dan pembahasan yang ada, maka dapat ditarik kesimpulan sebagai berikut :

1. Parameter yang berpengaruh pada Run $U p$ gelombang terdiri dari kerapatan screen layer $(\zeta)$, jumlah lapis screen layer $(N)$ jarak screen layer $(\mathrm{Xm})$, tinggi gelombang depan struktur $(H)$, panjang gelombang $(L)$ dan kedalaman air (d). Semakin besar kerapatan, jumlah lapis dan jarak bertambah serta kedalaman air kecil maka Run Up gelombang yang dihasilkan semakin kecil begitu juga sebaliknya.

2. Hasil pengujian screen layer breakwater dapat mereduksi tinggi Run Up sebesar 33\% dan menghasilkan hubungan bilangan tak berdimensi antara tinggi gelombang datang dan Run Up gelombang pada revetment dalam bentuk persamaan Error! Reference source not found., dimana Error! Reference source not found.; dengan nilai koefisien a dan $b$ masing-masing 2,9935 dan 0,1293.

Saran dan rekomendasi penelitian sebagai berikut :

1. Hasil penelitian ini dapat diaplikasikan dilapangan sesuai hasil parameter yang diperoleh pada pengujian model, namun tidak cocok untuk semua kondisi mengingat penurunan rumus yang dihasilkan hanya pada kondisi tertentu karena keterbatasan Laboratorium dan untuk pengaplikasian model Screen layer breakwater direkomendasikan menggunakan bahan bermaterial geotextile.

2. Beberapa parameter yang belum dikaji dalam penelitian ini antara lain parameter tinggi model $(\mathrm{Hm})$ tetap, kemiringan revetmen hanya $30^{\circ}$ dan jenis revetment impermeable sehingga memungkinkan untuk dilakukan penelitian lanjutan yang dapat digunakan sebagai refrensi dalam perencanaan bangunan pantai (revetment) yang aman terhadap Run $U p$ gelombang. 


\section{Ucapan Terima Kasih}

Ucapan terima kasih disampaikan kepada

Program Studi Teknik Kelautan Universitas Hasanuddin atas izin penggunaan tempat untuk penelitian dan semua pihak yang telah membantu.

\section{Daftar Pustaka}

[1] CERC. (1984). Shore Protection Manual, Departement of the Army Waterway Experiment Station, Corps of Engineers, Coastal Engineering Research Center, Fourth Editioan, U.S. Government Printing Office, Washington, Hampshire, London.

[2] Hendra. (2011). Pengaruh Pelindung Kaki Tipe Pancang Terhadap Run Up Gelombang pada Revetmen (Tesis). Makassar: Universitas Hasanuddin.

[3] Irribaren, C (1938). Una Formula par el Calculo de Digues de Escollera, Revista de Obras Publicas.

[4] Triatmodjo, B. (1999). Teknik Pantai. Beta Offset, Yogyakarta.

[5] Yuwono, Nur. (1996). Perencanaan Model Hidraulik. Laboratorium Hidraulik dan Hidrologi . Yogyakarta: Pusat Antar Univeristas Ilmu Teknik Univeristas Gadjah Mada. 